\title{
Directed search with real options
}

\author{
Article
}

Accepted Version

Wadeson, N. S. (2010) Directed search with real options. Economics of Innovation and New Technology, 19 (6). pp. 569582. ISSN 1476-8364 doi: https://doi.org/10.1080/10438599.2010.486527 Available at https://centaur.reading.ac.uk/16235/

It is advisable to refer to the publisher's version if you intend to cite from the work. See Guidance on citing.

To link to this article DOI: http://dx.doi.org/10.1080/10438599.2010.486527

Publisher: Routledge

All outputs in CentAUR are protected by Intellectual Property Rights law, including copyright law. Copyright and IPR is retained by the creators or other copyright holders. Terms and conditions for use of this material are defined in the End User Agreement.

\section{$\underline{\text { www.reading.ac.uk/centaur }}$}

\section{CentAUR}

Central Archive at the University of Reading

Reading's research outputs online 


\section{Directed search with real options}

Article

Accepted Version

Wadeson, N. S. (2010) Directed search with real options. Economics of Innovation and New Technology, 19 (6). pp. 569-582. ISSN 1476-8364 doi: $10.1080 / 10438599.2010 .486527$ Available at http://centaur.reading.ac.uk/16235/

It is advisable to refer to the publisher's version if you intend to cite from the work.

To link to this article DOI: http://dx.doi.org/10.1080/10438599.2010.486527

Publisher: Routledge

All outputs in CentAUR are protected by Intellectual Property Rights law, including copyright law. Copyright and IPR is retained by the creators or other copyright holders. Terms and conditions for use of this material are defined in the End User Agreement.

\section{www.reading.ac.uk/centaur}

\section{CentAUR}

Central Archive at the University of Reading

Reading's research outputs online 


\title{
Directed Search with Real Options
}

\author{
Nigel Wadeson
}

School of Economics, University of Reading, Reading, UK 


\title{
Directed Search with Real Options
}

\begin{abstract}
While search is normally modelled by economists purely in terms of decisions over making observations, this paper models it as a process in which information is gained through feedback from innovatory product launches. The information gained can then be used to decide whether to exercise real options. In the model the initial decisions involve a product design and the scale of production capacity. There are then real options to change these factors based on what is learned. The case of launching product variants in parallel is also considered. Under 'true' uncertainty the model can be seen in terms of heuristic decision making based on subjective beliefs with limited foresight. Search costs, the values of the real options, beliefs, and the cost of capital are all shown to be significant in determining the search path.
\end{abstract}

JEL Classifications: O30, D83, D92, M13

Key Words: Search, Real Option, Innovation, Feedback, Learning, Strategy 


\section{Introduction}

This paper integrates search and real options into a single model. By doing so, the aim is to demonstrate how both areas of theory can be made more relevant to innovation processes. Relevant case study evidence of firms following sequential and parallel approaches to product launches will be cited in the section following the model. For example, a firm may launch in a small niche market before making further commitments to address the mass market. Alternatively, it might launch a high risk product initially, knowing that if it fails then it can still attempt to gain value from its commitments through subsequently launching a related product. It might also face the choice of launching a range of products either simultaneously or sequentially.

Economic search theory (Lippman and McCall 1976), emanating from Stigler (1961), recognises that costly search will often not be exhaustive, involving the weighing of the costs and expected benefits of further search against each other. However, search theory in economics focuses mainly on one-dimensional searches across independently and identically distributed variables, normally prices or wages, and simply on when the search should terminate rather than what path it should take.

The path of search was a focus of Weitzman (1979) who considered the case of nonidentical distributions and of Wadeson (2004) who considered the case where search is multidimensional. This paper also addresses the path of search, but considers the case where information is gained through feedback from action, where those actions involve investments so that search involves real options. Search theory in economics normally involves just making observations rather than also making investments during search such as in production facilities. Note also that empirical work on research and development has tended to focus on search intensity (Chen and Miller 2007) rather than on search paths.

The often made assumption in economic search theory that the distributions being searched over are known in advance results in the aspiration level (or 'reservation price') staying constant during a search. In reality, for instance, if a search is going badly then beliefs might become more pessimistic and the aspiration level might be lowered (Morgan 1985) or the search abandoned. Without such behaviour searches could potentially continue on and on without finding solutions that satisfy pre-determined aspiration levels despite ever more evidence being gained that it is not worth continuing. A search could also be terminated even when a far superior solution is believed to be about to be found. The decision process modelled in this paper, on the other hand, involves interrelated beliefs. Gaining feedback information about one product variant affects beliefs about an alternative variant. It will be shown how this affects decisions over both the path and the termination of the search.

Another aspect of economic search theory concerns whether search should proceed in a sequential fashion, with one observation following another, or whether there should be parallel search, under which observations are made simultaneously (Nelson 1961; Vishwanath 1992). This has also been addressed using real options valuation methods 
(Childs, Ott, and Triantis 1998; Childs and Triantis 1999). The advantage of sequential search is that information gained so far can be used to decide when the search should terminate and what further path it should take. Parallel search can, however, be preferable where delay is costly and observations take a significant amount of time or where there are economies relating to the size of a batch of observations. Note that a search may, in fact, have both sequential and parallel aspects, with observations being made in a sequence of batches (Morgan and Manning 1985).

Real options theory (Johnson 2007) provides another theoretical perspective on sequential decision making. This has often been applied in terms of expansion, contraction, and abandonment options. For instance, a firm can gain new information while limiting the degree of sunk costs incurred by initially launching a project on a smaller scale, so limiting downside risk. The firm then has the options to expand capacity later on or to abandon the project. The literature also stresses switching options (Triantis and Hodder 1990). In the model that follows the firm has options to switch the use of a production facility from one newly developed good to another and, if initial scale is small, to expand it.

A criticism that has been made of real options literature is that it focuses on 'wait and see' decisions where the decision maker simply waits to see what some exogenous value will be before deciding whether to exercise an option. This is as opposed to endogenous uncertainty where the decision maker actively determines what information will be gathered (McGrath, Ferrier, and Mendelow 2004, 96-7). Integrating real options into search models addresses this criticism, extending real options reasoning to cover decisions over how to resolve endogenous uncertainty, and allowing insights to be gained into how real options help to determine search paths.

Theoretical approaches that consider ex post learning only in relation to scale and exit options provide only a partial picture. Scale is not the only way in which an innovation project can be adapted in response to feedback information. Other aspects, such as the product design, can also be adapted. As will been seen, the ability to adapt a project in such ways while it is under way affects the initial features of the project. Just as the ability to adapt the scale of a project ex post affects the initial choice of scale, so the ability to adapt other aspects of the project also affects choices over its initial characteristics. This then affects exactly what feedback information is gained during the project. Such arguments give a taste of how real options reasoning needs to be richer in cases of endogenous uncertainty.

One potentially important implication of viewing innovation as a sometimes long lasting process involving information feedback and adaptation concerns the way in which the cost of capital affects innovation strategies. It is clear that the level of interest rates, contributing to the costs of innovation, affects its level in an economy. However, a higher cost of capital also increases the relative costs of drawn-out learning processes, focusing attention more on nearer cash flows rather than those that might be achieved further into the future. The effects on the types of innovations that take place within an economy may be significant rather than just on their number. 


\section{The model}

The purpose of this model is to investigate project design choices and adaptation decisions in an innovative project. The model is designed to include a number of key factors in order to incorporate an innovative learning process: interrelated beliefs, an initial design choice with the possibility of changing it following ex post feedback information, and investments in product development, initial production capacity, and later expansion.

Innovation often involves significant 'true' uncertainty and a vast potential search space. Under such circumstances, the model can be seen in terms of a heuristic decision, representing the best choice that can be made given subjective beliefs about what might follow based on myopic foresight. This has a parallel in artificial intelligence where heuristic functions are used to choose the direction taken at each point in a search. Through the use of discrete time periods and discrete probability distributions the mathematical complexity of the model is reduced relative to option valuation methods that are based on the assumption of a stochastic process (the assumption of a stochastic process rather than an endogenous information process implies that an option concerns an underlying asset that is priced in an efficient market).

The modelling approach involves the simplifying assumption of binary choices. Rather than maximising a single equation, a set of equations is set out. Each equation represents a possible strategy. The question is then under what conditions each strategy is superior. This is explored through a set of inequalities. Under such a modelling approach the use of binary choices is useful in restricting the range of possible strategies to a manageable level. So, for instance, choices over size are simplified to a choice between a larger and a smaller size.

It is assumed that there are two alternative, related product variants: Goods 1 and 2. Prior to launching the project the firm's risk neutral decision maker (for simplicity, assume the decision maker to be unitary) has subjective beliefs about the state of demand for each variant. The firm learns the true state of demand for a variant by putting it into production.

The model involves a range of alternative strategies. The strategy dimensions include the questions of which variant to develop and launch first or whether to develop both at once, how large an investment in capacity to make initially, whether the second product should be developed conditional on the state of demand for the first, whether the project should be started at all, and when it should be terminated.

$\delta$ is the discount factor. So with a cost of capital per period of $\mathrm{r}$ :

$$
\delta=\frac{1}{1+\mathrm{r}}
$$


$F_{s}$ is the cost of smaller-scale production facilities. $F_{B}$ is the cost of larger-scale production facilities. Depending on whether initial production is on the smaller or larger scale, one of these costs is assumed to be incurred in the first period. Note that 'largerscale' does not necessarily mean very large scale. Rather the terms 'larger-scale' and 'smaller-scale' are employed to represent a choice over scale, including cases where the degree of choice is relatively small. If the project is terminated then a scrap value is realized. The scrap value is $s_{S}$ where the production facilities are smaller-scale, and $s_{B}$ where production facilities are larger-scale.

No matter which of the two goods is developed first, a development cost of D has to be incurred. This reflects the fact that the development of one good may also take the firm some way towards developing the second good where they share some underlying technology or common features. Where there is no such relationship the value of D is zero. There is then a further cost of developing each good in order to put it into production. These costs are $\mathrm{D}_{1}$ and $\mathrm{D}_{2}$ respectively. It takes one time period to develop a good so that it can then be produced in the subsequent period. So, if Good 1 is developed in the first time period then the cost of this is $D+D_{1}$ and if this is followed by the development of Good 2 in the second time period then the additional cost is $\mathrm{D}_{2}$.

Demand for each good, when it is the only one of the two produced, is assumed to have either a higher or a lower value. Ex ante the firm attaches a probability $\mathrm{p}_{1 \mathrm{~L}}$ to demand for Good 1 being low, and therefore a probability $\mathrm{p}_{1 \mathrm{H}}=1-\mathrm{p}_{1 \mathrm{~L}}$ to it being high. Similarly the firm attaches the probability $\mathrm{p}_{2 \mathrm{~L}}$ to demand for Good 2 being low, and $\mathrm{p}_{2 \mathrm{H}}$ to it being high. If the firm has invested in smaller-scale capacity then, if demand is high, production can be expanded at the start of the next period at a cost of $\mathrm{E}$.

The goods are similar to each other to some degree, and hence observing that one of the goods has low demand causes a upward revision in the probability that the other good has low demand. For instance, the relationship will tend to be strong where the goods are quite similar and address the same customers. Alternatively, they might address different markets but be applications of the same underlying technology and the performance of that technology might be a source of prior uncertainty. On the other hand, the relationship may be weak where one good is aimed at correcting the flaws of another.

The prior probability that both goods have low demand is denoted $\mathrm{p}_{1 \mathrm{~L} 2 \mathrm{~L}}$. Other joint probabilities are notated in a similar fashion. Conditional probabilities are denoted in the form $\mathrm{p}_{1 \mathrm{~L} \cdot 2 \mathrm{~L}}$ (this example being the probability that Good 1 has low demand given that Good 2 has low demand).

At the start of the development of a good the present value of the profits for all future periods if demand for it is high, and if it is the only good produced, is represented by $\delta \pi$. Note that the $\pi$ term, which is subscripted below to identity the good concerned, is decreasing with cost of capital $\left(\pi^{\prime}(r)<0\right)$. For instance, if the profit stream is an annuity, a, for all future periods then $\pi=\mathrm{a} / \mathrm{r}$. Assume, for simplicity, that the profits for a good with low demand or that is produced on a small scale are zero. 
Define $\mathrm{x}$ as the difference in the profitability of producing both goods simultaneously as compared to the sum of the profitabilities of producing each of the two goods alone. So, if each good would have high demand if it were the only one in production, then if both goods are produced the present value of the profit stream is $\pi_{1}+\pi_{2}+x$. The value of $x$ could be positive or negative depending on the relationship between the two goods. In some circumstances it will only ever be worth producing one of the goods $\left(\mathrm{x}<-\pi_{1}\right.$ or $\mathrm{x}<-$ $\pi_{2}$ ). For instance, one good may essentially be a better developed version of another. Alternatively, the goods might be complements in consumption, in which case selling both together would increase the demand for each product which could result in a positive value of $\mathrm{x}$. On the other hand, they might be substitutes in consumption, in which case selling both goods simultaneously could reduce demand for each individual good, though offering a range of alternative goods could have the opposite effect, such as through a stronger shared brand. If either good has low demand then, for simplicity, it is assumed that the profits for the single period of joint production are the same as if only the high demand good had been produced.

\section{Small-first, non-parallel strategies with termination of search on initial success}

The expected values of the alternative strategies will now be considered. The first strategies are those where if the first good produced has high demand then it continues in production; the second good is not then developed.

Strategy 1S. This strategy involves production of Good 1 on a smaller scale. If demand for Good 1 is low then the project is abandoned. If demand is high then production capacity is expanded and production of Good 1 continues on a larger scale. It is assumed that the same profit, less the expansion cost E, will be earned from larger-scale production beginning in the second period as if production facilities had been on a larger scale from the outset. The expected value of the strategy is therefore:

$$
\mathrm{v}_{1 \mathrm{~S}}=-\mathrm{F}_{\mathrm{s}}-\mathrm{D}-\mathrm{D}_{1}+\delta \mathrm{p}_{1 \mathrm{H}}\left(\pi_{1}-\mathrm{E}\right)+\delta \mathrm{p}_{1 \mathrm{~L}} \mathrm{~s}_{\mathrm{S}}
$$

Strategy 1S2. This is the same as Strategy $1 \mathrm{~S}$ except that if demand for Good 1 turns out to be low then Good 2 is developed in the next period. Hence, under this strategy, iteration is driven by initial failure and despite the negative information that this gives regarding the prospects for the second good. The project is abandoned if there turns out to be low demand for both Goods 1 and 2. For simplicity, it is assumed that production of a good in one period has no effect on the profitability of production of the other good in the

next period, other than the fact that it is discounted by a period. The expected value is:

$$
\mathrm{v}_{1 \mathrm{~S} 2}=-\mathrm{F}_{\mathrm{s}}-\mathrm{D}-\mathrm{D}_{1}+\delta \mathrm{p}_{1 \mathrm{H}}\left(\pi_{1}-\mathrm{E}\right)+\delta \mathrm{p}_{1 \mathrm{~L}}\left(-\mathrm{D}_{2}+\delta \mathrm{p}_{2 \mathrm{~L} \bullet \mathrm{L}} \mathrm{s}_{\mathrm{S}}+\delta \mathrm{p}_{2 \mathrm{H} \bullet \mathrm{L}}\left(\pi_{2}-\mathrm{E}\right)\right)
$$

Strategy $1 \mathrm{~S} 2$ is superior to Strategy $1 \mathrm{~S}$ if:

$$
\delta \mathrm{p}_{2 \mathrm{H} \bullet \mathrm{L}}\left(\pi_{2}-\mathrm{E}\right)>\left(1-\delta \mathrm{p}_{2 \mathrm{~L} \bullet \mathrm{L}}\right) \mathrm{s}_{\mathrm{S}}+\mathrm{D}_{2}(4)
$$


Start-up, continuation and growth of the project are more likely if the option to trial production of Good 2 when Good 1 has been found to have low demand is valuable. The option's value is increasing with the probability that Good 2 is profitable and with the level of associated profit. It is decreasing with Good 2's development cost, the scrap value, the strength of discounting (and, by implication, the length of the time period involved), and the strength of the interrelationship between the states of demand for the two goods.

\section{Large-first, non-parallel strategies with termination of search on initial success}

Now strategies where the project begins on a larger scale will be considered. The firm could invest in larger-scale facilities before producing Good 1, pursuing Strategy 1B under which the project then terminates if demand for Good 1 is low. The expected value is then:

$$
\mathrm{v}_{1 \mathrm{~B}}=-\mathrm{F}_{\mathrm{B}}-\mathrm{D}-\mathrm{D}_{1}+\delta \mathrm{p}_{1 \mathrm{H}} \pi_{1}+\delta \mathrm{p}_{1 \mathrm{~L}} \mathrm{~s}_{\mathrm{B}}
$$

Alternatively, under Strategy 1B2, if demand for Good 1 turns out to be low then production is switched to Good 2. Again, iteration is here driven by the failure of the first good and despite the negative information that this gives regarding the second good. If demand for Good 2 is also low then the project is then terminated. The expected value of Strategy 1B2 is:

$$
\mathrm{v}_{1 \mathrm{~B} 2}=-\mathrm{F}_{\mathrm{B}}-\mathrm{D}-\mathrm{D}_{1}+\delta \mathrm{p}_{1 \mathrm{H}} \pi_{1}+\delta \mathrm{p}_{1 \mathrm{~L}}\left(-\mathrm{D}_{2}+\delta \mathrm{p}_{2 \mathrm{H} \bullet 1 \mathrm{~L}} \pi_{2}+\delta \mathrm{p}_{2 \mathrm{~L} \bullet \mathrm{L}} \mathrm{s}_{\mathrm{B}}\right)
$$

Strategy 1B2 is preferred to Strategy 1B, giving a lower probability of the abandonment of the project, if:

$$
\delta \mathrm{p}_{2 \mathrm{H} \bullet 1 \mathrm{~L}} \pi_{2}>\left(1-\delta \mathrm{p}_{2 \mathrm{~L} \bullet 1 \mathrm{~L}}\right) \mathrm{s}_{\mathrm{B}}+\mathrm{D}_{2}
$$

Note the 'sunk cost effect' on the product choice decision. Sunk costs help to drive adaptation in the face of initial failure, rather than simply the continuation of production. Sunk costs can encourage the exploration of the remaining good by increasing the net payoff if successful. So, for instance, following production of Good 1 and having found low demand for it, the value of the option to trial production of Good 2 is greater if production facilities are on a larger-scale by the amount:

$$
\delta \mathrm{p}_{2 \mathrm{H} \bullet \mathrm{L}} \mathrm{E}-\left(1-\delta \mathrm{p}_{2 \mathrm{~L} \cdot \mathrm{L}}\right)\left(\mathrm{s}_{\mathrm{B}}-\mathrm{s}_{\mathrm{S}}\right)
$$

Now consider an example of the choice of whether to produce on a larger or smaller scale. Strategy $1 \mathrm{~S} 2$ is preferred to Strategy $1 \mathrm{~B} 2$ if $\mathrm{v}_{1 \mathrm{~S} 2}>\mathrm{v}_{1 \mathrm{~B} 2}$. This equates to:

$$
\mathrm{F}_{\mathrm{B}}-\mathrm{F}_{\mathrm{S}}>\delta^{2} \mathrm{p}_{1 \mathrm{~L} 2 \mathrm{~L}}\left(\mathrm{~s}_{\mathrm{B}}-\mathrm{s}_{\mathrm{S}}\right)+\delta\left(\mathrm{p}_{1 \mathrm{H}}+\delta \mathrm{p}_{1 \mathrm{~L} 2 \mathrm{H}}\right) \mathrm{E}
$$


The saving in initial outlay for smaller-scale production facilities is set against the later, and hence discounted but potentially greater, expansion cost. Stronger discounting increases the weighting of $F_{B}-F_{S}$ relative to the later expansion costs. Larger initial scale is encouraged by higher probabilities of high demand for both goods, and also by a weak relationship between the states of demand for the two goods. These factors combine with the sunk cost effect mentioned above to help explain why larger initial scale may be associated with a lower probability of project abandonment (for instance, Geroski (1995) notes an association between the size of an entrant and its chances for survival but this is often interpreted in relation to the proximity to the minimum efficient scale). An exception to this is where larger initial scale is encouraged by a high associated scrap value.

The equivalent expressions for when Good 2 is produced first are symmetrical to Expressions 2 to 9. Consider an example of the choice between producing Good 1 first versus producing Good 2 first. Strategy $1 \mathrm{~B} 2$ is preferred to Strategy $2 \mathrm{~B} 1$ if $\mathrm{v}_{1 \mathrm{~B} 2}>\mathrm{V}_{2 \mathrm{~B} 1}$. This equates to:

$$
\delta \mathrm{p}_{1 \mathrm{H}} \pi_{1}+\delta^{2} \mathrm{p}_{1 \mathrm{~L} 2 \mathrm{H}} \pi_{2}-\mathrm{D}_{1}-\delta \mathrm{p}_{1 \mathrm{~L}} \mathrm{D}_{2}>\delta \mathrm{p}_{2 \mathrm{H}} \pi_{2}+\delta^{2} \mathrm{p}_{1 \mathrm{H} 2 \mathrm{~L}} \pi_{1}-\mathrm{D}_{2}-\delta \mathrm{p}_{2 \mathrm{~L}} \mathrm{D}_{1}
$$

The expected payoff when a particular good is produced first consists of the expected payoff relating to that good alone, plus the value of the option to go on a produce the second good. Where the associated option value is high a good with low expected value, but with some potential for a very high level of profitability, may be produced first. The option value is reduced if discounting is strong. Hence projects with high costs of capital will tend to be designed to incorporate less uncertainty, such as where an incremental innovation with a relatively high probability of moderate profitability is pursued.

\section{Antecedent strategies (which involve iteration after initial success)}

A further class of strategies will be termed 'Antecedent'. These exploit the relationship between the two goods in order to economise on development costs. One good is produced and if demand for it turns out to be high then the other good is developed in the next period and then put into production. In other words, if the information gained from the first good is positive then this gives increased confidence in incurring the costs of developing the second good. If it is negative then this leads to the costs of developing the second good being avoided. The first good might not have the potential to be profitable itself but could be used to sound out the prospects for the second. Alternatively, it might be hoped that both goods will be profitable but make sense to discover the state of demand for the first before incurring the costs of developing of the second.

Under Strategy A2S Good 2 is first produced on a smaller scale. If demand for Good 2 is high then Good 1 is developed and then put into production. Production may be expanded once Good 2 has been found to have high demand or, if Good 2 is not worth producing in its own right $\left(\pi_{2}<0\right)$, only once Good 1 has also been found to have high demand. If demand for Good 1 is low then either production reverts to Good 2 (if $\pi_{2}>0$ ) or the project is abandoned. As Good 2 may now be produced on a larger scale for a single time 
period while Good 1 is being developed, assume for simplicity that the profit made from it in this period is $(1-\delta) \pi_{2}$ and so the present value of profits for subsequent periods if it continues as the only good in production is $\delta \pi_{2}$. Similarly, if production switches to Good 1 alone then the present value of profits for subsequent periods is $\delta \pi_{1}$, or $\delta\left(\pi_{1}+\pi_{2}+x\right)$ if production instead switches to both goods being produced. The expected value of the strategy is therefore:

$$
\mathrm{v}_{\mathrm{A} 2 \mathrm{~S}}=-\mathrm{F}_{\mathrm{S}}-\mathrm{D}-\mathrm{D}_{2}+\delta \mathrm{p}_{2 \mathrm{H}}\left(\begin{array}{l}
-\mathrm{D}_{1}+\operatorname{Max}\left[-\mathrm{E}+(1-\delta) \pi_{2}+\delta \mathrm{p}_{1 \mathrm{H} \bullet 2 \mathrm{H}} \operatorname{Max}\left[\pi_{1}, \pi_{1}+\pi_{2}+\mathrm{x}\right]\right. \\
\left.+\delta \mathrm{p}_{1 \mathrm{~L} \bullet 2 \mathrm{H}} \pi_{2}, \delta \mathrm{p}_{1 \mathrm{H} \bullet 2 \mathrm{H}}\left(\operatorname{Max}\left[\pi_{1}, \pi_{1}+\pi_{2}+\mathrm{x}\right]-\mathrm{E}\right)+\delta \mathrm{p}_{1 \mathrm{~L} \bullet 2 \mathrm{H}} \mathrm{s}_{\mathrm{S}}\right]
\end{array}\right)+\delta \mathrm{p}_{2 \mathrm{~L}} \mathrm{~s}_{\mathrm{S}}
$$

And the equivalent strategy when initial capacity is on a larger scale, $\mathrm{A} 2 \mathrm{~B}$, has the expected value:

$$
\mathrm{v}_{\mathrm{A} 2 \mathrm{~B}}=-\mathrm{F}_{\mathrm{B}}-\mathrm{D}-\mathrm{D}_{2}+\delta \mathrm{p}_{2 \mathrm{H}}\left(\begin{array}{l}
-\mathrm{D}_{1}+(1-\delta) \pi_{2}+\delta \mathrm{p}_{1 \mathrm{H} \bullet 2 \mathrm{H}} \operatorname{Max}\left[\pi_{1}, \pi_{1}+\pi_{2}+\mathrm{x}\right] \\
+\delta \mathrm{p}_{1 \mathrm{~L} \bullet 2 \mathrm{H}} \operatorname{Max}\left[\pi_{2}, \mathrm{~s}_{\mathrm{B}}\right]
\end{array}\right)+\delta \mathrm{p}_{2 \mathrm{~L}} \mathrm{~s}_{\mathrm{B}}
$$

As an example to show under what conditions antecedent strategies are preferred, Strategy A2B is preferred to Strategy $1 \mathrm{~B}$, for the case of $\pi_{2} \leq \mathrm{s}_{\mathrm{B}}$ and $\mathrm{x} \leq-\pi_{2}$, where:

$$
\left(1-\delta \mathrm{p}_{2 \mathrm{H}}\right) \mathrm{D}_{1}+\delta\left(\mathrm{p}_{2 \mathrm{~L}}-\mathrm{p}_{1 \mathrm{~L}}\right) \mathrm{s}_{\mathrm{B}}+\delta^{2} \mathrm{p}_{1 \mathrm{~L} 2 \mathrm{H}} \mathrm{s}_{\mathrm{B}}+\delta(1-\delta) \mathrm{p}_{2 \mathrm{H}} \pi_{2}>\mathrm{D}_{2}+\delta\left(\mathrm{p}_{1 \mathrm{H}}-\delta \mathrm{p}_{1 \mathrm{H} 2 \mathrm{H}}\right) \pi_{1}
$$

Antecedent strategies are more effective if the goods are significantly interrelated in such a way that the first good produced having high demand is a good indicator of the remaining good having high demand, and when the prior probabilities of the goods having high demand are low. They are also favoured where the first good produced has a significantly lower development cost. They are favoured relative to non-antecedent sequential strategies where the goods can be profitably produced together (i.e. where $\mathrm{x}$ is positive).

In addition, Good 1 could be produced first, giving symmetrical expressions to those above.

\section{Parallel Strategies}

Parallel strategies involve the simultaneous development of both goods, so saving time as compared to sequential strategies in which one good may be developed after the other. For simplicity, it is assumed that customer feedback is such that the same information on the states of demand for the two goods is gained as would have been the case had they had been developed sequentially, and that this information is gained at the start of the first period of production. Following parallel development, it is therefore known at the start of 
the second time period what the state of demand will be should only one good then continue in production.

The initially smaller-scale parallel strategy, PS, gives an expected value of:

$$
\mathrm{v}_{\mathrm{PS}}=-\mathrm{F}_{\mathrm{S}}-\mathrm{D}-\mathrm{D}_{1}-\mathrm{D}_{2}+\delta\left(\begin{array}{l}
\mathrm{p}_{1 \mathrm{~L} 2 \mathrm{~L}} \mathrm{~s}_{\mathrm{S}}+\mathrm{p}_{1 \mathrm{H} 2 \mathrm{~L}} \operatorname{Max}\left[\pi_{1}-\mathrm{E}, \mathrm{s}_{\mathrm{s}}\right] \\
+\mathrm{p}_{1 \mathrm{H} 2 \mathrm{H}}\left(\operatorname{Max}\left[\pi_{1}, \pi_{2}, \pi_{1}+\pi_{2}+\mathrm{x}\right]-\mathrm{E}\right) \\
+\mathrm{p}_{1 \mathrm{~L} 2 \mathrm{H}} \operatorname{Max}\left[\pi_{2}-\mathrm{E}, \mathrm{s}_{\mathrm{s}}\right]
\end{array}\right)
$$

The larger-scale parallel strategy, PB, gives an expected payoff of:

$$
\mathrm{v}_{\mathrm{PB}}=-\mathrm{F}_{\mathrm{B}}-\mathrm{D}-\mathrm{D}_{1}-\mathrm{D}_{2}+\delta\left(\begin{array}{l}
\mathrm{p}_{1 \mathrm{~L} 2 \mathrm{~L}} \mathrm{~s}_{\mathrm{B}}+\mathrm{p}_{1 \mathrm{H} 2 \mathrm{~L}} \operatorname{Max}\left[\pi_{1}, \mathrm{~s}_{\mathrm{B}}\right] \\
+\mathrm{p}_{1 \mathrm{H} 2 \mathrm{H}} \operatorname{Max}\left[\pi_{1}, \pi_{2}, \pi_{1}+\pi_{2}+\mathrm{x}\right] \\
+\mathrm{p}_{1 \mathrm{~L} 2 \mathrm{H}} \operatorname{Max}\left[\pi_{2}, \mathrm{~s}_{\mathrm{B}}\right]
\end{array}\right)
$$

Strategy PS is therefore preferred to Strategy PB (for the case where $\pi_{1}, \pi_{2} \geq \mathrm{S}_{\mathrm{s}}+\mathrm{E}$ ) if:

$$
\mathrm{F}_{\mathrm{B}}-\mathrm{F}_{\mathrm{S}}>\delta\left(\mathrm{p}_{1 \mathrm{~L} 2 \mathrm{~L}}\left(\mathrm{~s}_{\mathrm{B}}-\mathrm{s}_{\mathrm{S}}\right)+\left(1-\mathrm{p}_{1 \mathrm{~L} 2 \mathrm{~L}}\right) \mathrm{E}\right)
$$

Note the increased incentive for parallel strategies to be large-first relative to sequential strategies.

As an example of where parallel strategies are preferred over sequential ones, for the case of $\pi_{1}>\pi_{2}$ and $\mathrm{x} \leq-\pi_{2}$, Strategy PB is preferred over Strategy 1B2 where:

$$
\delta(1-\delta)\left(\mathrm{p}_{1 \mathrm{~L} 2 \mathrm{~L}} \mathrm{~s}_{\mathrm{B}}+\mathrm{p}_{1 \mathrm{~L} 2 \mathrm{H}} \pi_{2}\right)>\left(1-\delta \mathrm{p}_{1 \mathrm{~L}}\right) \mathrm{D}_{2}(17)
$$

Parallel strategies have the advantage of being able to more quickly abandon the project if both goods have low demand and therefore to realise the scrap value. A further advantage is being able to more quickly realise the profits resulting from producing the good that would be developed second under a sequential strategy. Parallel strategies are therefore favoured by strong discounting, a low cost of developing the second good, a high scrap value, and a high potential level of profitability from producing the second good (including the joint effect on profitability, $\mathrm{x}$ ). Note that one case where the cost of developing the second good would be low would be where most of the development cost was accounted for by the shared development cost, D.

\section{The Null Strategy}

Finally, the firm has the option to pursue the Null Strategy of not starting the project at all. This gives the value: 


$$
\mathrm{v}_{0}=0
$$

Naturally the expected value of starting up the project is improved by high probabilities of high levels of profit and by low costs. However it is also enhanced by the values of the expansion and product choice options inherent in the chosen strategy. The ability to adapt to feedback once the project is under way is therefore a key aspect of the start-up decision.

\section{Graphical illustrations of the model}

A graphical illustration of the model is given in Figure 1. Each region of the graph shows where a particular strategy is optimal, and is labelled with the name of the strategy. The figure is based on a set of parameter values chosen for expository purposes. Small-First Strategies occupy the top-right of the graph, where the prior probabilities of the goods having low demand are relatively high. Non-antecedent sequential strategies occupy the bottom-left of the graph, where the prior probabilities of the goods having low demand are relatively low. An antecedent strategy occupies the top-right corner of the graph, where the prior probabilities of the goods having low demand are relatively high. This illustrates that antecedent strategies can play a key role in more radical innovations, allowing them to go ahead despite a low probability of success.

\section{Insert Figure 1 around here}

Figure 2 represents the same parameter values as Figure 1, except that the cost of capital is higher. An increase in the cost of capital reduces the present values of the profit streams. This could make the project unprofitable under any strategy, as shown by the appearance of the Null Strategy in the top-right of Figure 2. Antecedent strategies become less attractive, due to the time consuming experimentation process that they embody. In addition, the region of Strategy 2B is much wider in Figure 2 than in Figure 1. This reflects the fact that, with a higher cost of capital, a less profitable but less uncertain product becomes relatively more attractive compared to a more uncertain, but potentially more profitable, product. The less uncertain product is likely to yield a return quickly, whereas the more uncertain product is more likely to entail a time consuming process of adaptation before a return is made. In other words, the values of options for future adaptation are more heavily discounted with a higher cost of capital, so that more weight is put on achieving a return early on.

\section{Insert Figure 2 around here}

Hence, a higher interest rate economy is likely to have not only less innovations, but also more conservative innovations. The economy will be less innovative in both these respects, resulting in lower growth. This view results from the assumption that some types of innovation strategies involve time consuming learning-through-feedback processes. 
Figure 3 shows a form of higher optimism. It represents the same parameter values as Figure 1, except that there is a weaker relationship between the probabilities of the states of demand for the two goods. If there turns out to be low demand for the first good produced then there will be a higher subjective probability of the second good having high demand than is the case in Figure 1. This dimension of optimism is another factor that results from viewing innovation as a process involving feedback and adaptation. Rather than viewing optimism simply in terms of the probability of success of a single product, it is also viewed in terms of the firm's beliefs about whether the project can be adapted after initial feedback. The adaptability of a project would depend on the firm's own capabilities, the inherent adaptability of the technology (including the ways in which it can be marketed), and the flexibility of the assets in which the firm invests.

\section{Insert Figure 3 around here}

It can be seen in Figure 3, as compared to Figure 1, that the region occupied by the larger-scale iterative strategy, 1B2, has become much larger. It is now much more worthwhile continuing to the second good after the failure of the first. In addition, the region occupied by antecedent strategies, which exploit the relationship between the goods to reduce initial development costs, has shrunk considerably.

Figure 4 can be interpreted in terms of the lengths of the time periods in the model having been extended substantially. It now takes much longer to develop each good. This is reflected in a higher cost of capital per time period and a higher profit per time period. The present values of the profit streams are also set at higher levels than before, reducing the importance of strategies only ever involving the development of a single good.

The figure is included in order to illustrate the effectiveness of parallel strategies. The general pattern of the strategies is similar to that in Figure 3 except that the parallel strategies now dominate the bottom-right corner. In pursuing a parallel strategy, the firm is hoping that Good 1, having higher potential profitability, will have high demand. However, in the bottom right of the figure, Good 1 has relatively little chance of having high demand while Good 2 has a high chance. Due to strong discounting per time period, it is not worth following an sequential strategy which would delay the development of Good 2 until Good 1 has been found to have low demand.

\section{Insert Figure 4 around here}

\section{Real options reasoning}

Real options reasoning suggests limiting commitments in the face of uncertainty. Options to expand on initial commitments can then be exercised if things turn out favourably. However, exactly how and under what conditions should commitments be limited when the uncertainty that is faced is endogenous? The model has addressed these issues. 
One means by which commitments can be limited in the model is through the flexibility of the product choice and of the production facilities. It can make sense to develop a good with a high chance of failure if, once it has failed, a different good (which could be a modified version of the first good) can be developed, perhaps at little extra cost, which can be produced with the same facilities. Note that adaptation options are sometimes deliberately built into designs (Thomke and Reinertsen 1998; Gil 2007).

Such flexibility also affects the incentive to limit scale. It may make sense not to limit the scale of production faculties if initial failure can be quickly addressed through changes to the product. On the other hand, if product adaptation is likely to be a lengthy process then it is more likely to make sense to limit initial production capacity. For instance, a new product might be subjected to test marketing and then be quickly revised before a full product launch. On the other hand, initial experience of producing and selling a new product might lead to a more major and time consuming redesign process.

Commitments are limited through sequential strategies. If things turn out well with the first good under non-antecedent strategies, or if the feedback information gained from the production of the first good developed under an antecedent strategy is negative, then the costs of developing the second good are avoided. Under antecedent strategies it may be possible to limit initial development costs by first developing a good with low development costs. An example is given by McGrath, Ferrier, and Mendelow (2004: 95). A project team initially had plans for major investments in Bluetooth devices. However, it was decided instead to focus initially on small markets, solving demonstrated problems. It was therefore not just the planned initial scale that was altered but also the initial products. Indeed, some view the exploitation of niche applications as being essential to the process of discontinuous innovation within an economy (Schot and Geels 2008). Lynn, Morone, and Paulson (1996) provide case studies of firms learning through the production of early versions of new products sold in 'plausible' initial markets. Rice, Leifer, and O'Connor $(2002,314)$ also observed several examples of projects which followed a strategy of producing early niche applications.

The model has also shown under what circumstances parallel strategies are preferred, however. These have the advantage of more quickly realising the scrap value of the project if both goods have low demand or of gaining the profits that might result from putting a second good into production. They therefore also involve a diminished incentive to limit initial production capacity.

An example of parallel development can be seen in Norling and Statz (1998). After an initial technology, ionomer plastics, was developed, a $£ 30 \mathrm{~m}$ p.a. plant was authorised in 1964 and a number of products applying the technology were developed simultaneously. The firm may well have been overoptimistic in terms of how long it would take to perfect the applications and to then generate enough sales to justify the investment in the plant but this is not to say that the strategy was an incorrect choice given the subjective beliefs of those involved. Leonard-Barton (1998, 207-212) notes examples of both parallel experimentation and also of iterative strategies where market feedback from a first product is used to alter the next model, so that the product iterates towards a profitable 
version. Maidique and Zirger (1985) give evidence of learning from new product failures leading to subsequent successes.

\section{Conclusion}

This paper has explored innovation strategies by considering the economics of search processes involving real options. One intention was to explore the relevance of the economics of search to innovation processes. Another aim was to illustrate how real options reasoning needs to be enhanced when applied to situations of endogenous uncertainty. It is, however, necessary to recognise that innovation involves 'true' uncertainty and so decisions over search can be seen as involving heuristic reasoning based on subjective beliefs rather than perfect foresight and objective probabilities.

The logic of the strategies involved centres on option value and on efficient sequencing. Because important information is collected as a by-product of launching products, the firm needs to make adaptations ex post, rather than collecting all relevant information and making final decisions about the characteristics of the product prior to launch. The fact that the product can be adapted ex post also has important implications for the choices of the initial product and the scale of initial capacity.

In the model, iteration can result from either initial failure or through gaining feedback information from initial production that has a positive effect on beliefs about the prospects for an alternative product variant. These factors impact on the path of the search. The former motive for iteration can encourage the firm to try out a product that is likely to fail because it can subsequently go on and try to achieve success with an alternative product variant. The latter motive for iteration can encourage the firm to learn by first launching products into small niche markets or products which are basic prior to committing to more extensive development efforts and to larger scale. It also provides a logic for launching a range of products sequentially though the model also explored the alternative of parallel product launches.

The model predicts that the cost of capital can be an important influence. For instance, a high cost of capital can encourage not only either not starting a project, or starting it on a smaller initial scale, but also a less radical innovation. A more conservative innovation may allow the firm to be more certain of achieving profitability relatively quickly, rather than first having to go through a more lengthy process of adaptation. So higher interest rates not only reduce the number of innovative projects in an economy, but also affect their nature.

A further aspect of the model concerns the ways in which initial subjective beliefs impact on the strategy choice. Optimism is determined not only by how confident the firm is of initial success, but also whether it expects to be able to successfully adapt the project if necessary. Overoptimistic managers might invest too heavily early on. Such overinvestment could include not just capacity but also the wrong initial product design choices. For instance, substantial investments might be made to enter the mass market rather than first addressing smaller scale, more specialist applications. 


\section{References}

Chen, W. and K. Miller 2007. Situational and institutional determinants of firms' R\&D search intensity. Strategic Management Journal 28: 369-381.

Childs, P. and A. Triantis 1999. Dynamic R\&D investment policies. Management Science 45: 1359-1377.

Childs, P., S. Ott, and A. Triantis 1998. Capital budgeting for interrelated projects: A real options approach. Journal of Financial \& Quantitative Analysis 33: 305-334.

Geroski, P.A. 1995. What do we know about entry? International Journal of Industrial Organization 13: 421-440.

Gil, N. 2007. On the value of project safeguards: Embedding real options in complex products and systems. Research Policy 36: 980-999.

Johnson, W. 2007. Managing uncertainty in innovation: the applicability of both real options and path dependency theory. Creativity \& Innovation Management 16: 274-281.

Leonard-Barton, D. 1998. Wellsprings of Knowledge: Building and Sustaining the Sources of Innovation. Harvard Business School Press Books.

Lippman, S.A. and J.J. McCall 1976. The economics of job search: A survey. Economic Inquiry 14: 155-89.

Lynn, G.S., J.G. Morone, and A.S. Paulson 1996. Marketing and discontinuous innovation: The probe and learn process. California Management Review 38: 8-37.

Maidique, M.A. and B.J. Zirger 1985. The new product learning cycle. Research Policy 14: 299-313.

McGrath, R., W. Ferrier, and A. Mendelow 2004. Real options as engines of choice and heterogeneity. Academy of Management Review 29: 86-101.

Morgan, P.B. 1985. Distributions of the duration and value of job search with learning. Econometrica 53: 1199-1232.

Morgan, P. and R. Manning 1985. Optimal search. Econometrica 53: 923-44.

Nelson, R.R. 1961. Uncertainty, learning, and the economics of parallel research and development efforts. Review of Economics and Statistics 43: 351-64.

Norling, P. R. and R. Statz 1998. How discontinuous innovation really happens. Research Technology Management 41: 41-44. 
Rice, M., R. Leifer and G. O'Connor 2002. Commercializing discontinuous innovations: bridging the gap from discontinuous innovation project to operations. IEEE Transactions on Engineering Management 49: 330-340.

Schot, J. and F. Geels 2008. Strategic niche management and sustainable innovation journeys: theory, findings, research agenda, and policy. Technology Analysis \& Strategic Management 20: 537-554.

Stigler, G.J. 1961. The economics of information. The Journal of Political Economy 69: 213-225.

Thomke, S. and D. Reinertsen 1998. Agile product development: Managing development flexibility in uncertain environments. California Management Review 41: 8-30.

Triantis, A.J. and J.E. Hodder 1990. Valuing flexibility as a complex option. The Journal of Finance 45: 549-565.

Vishwanath, T. 1992. Parallel search for the best alternative. Economic Theory 2: 495507.

Wadeson N. 2004. Multi-dimensional search: choosing the right path. International Journal of the Economics of Business 11: 287-301.

Weitzman. M. 1979. Optimal search for the best alternative. Econometrica 47: 641-654. 
Figure 1: $r=0.03 ;$ Ana $15 \mathbf{P} \mathbf{2}$

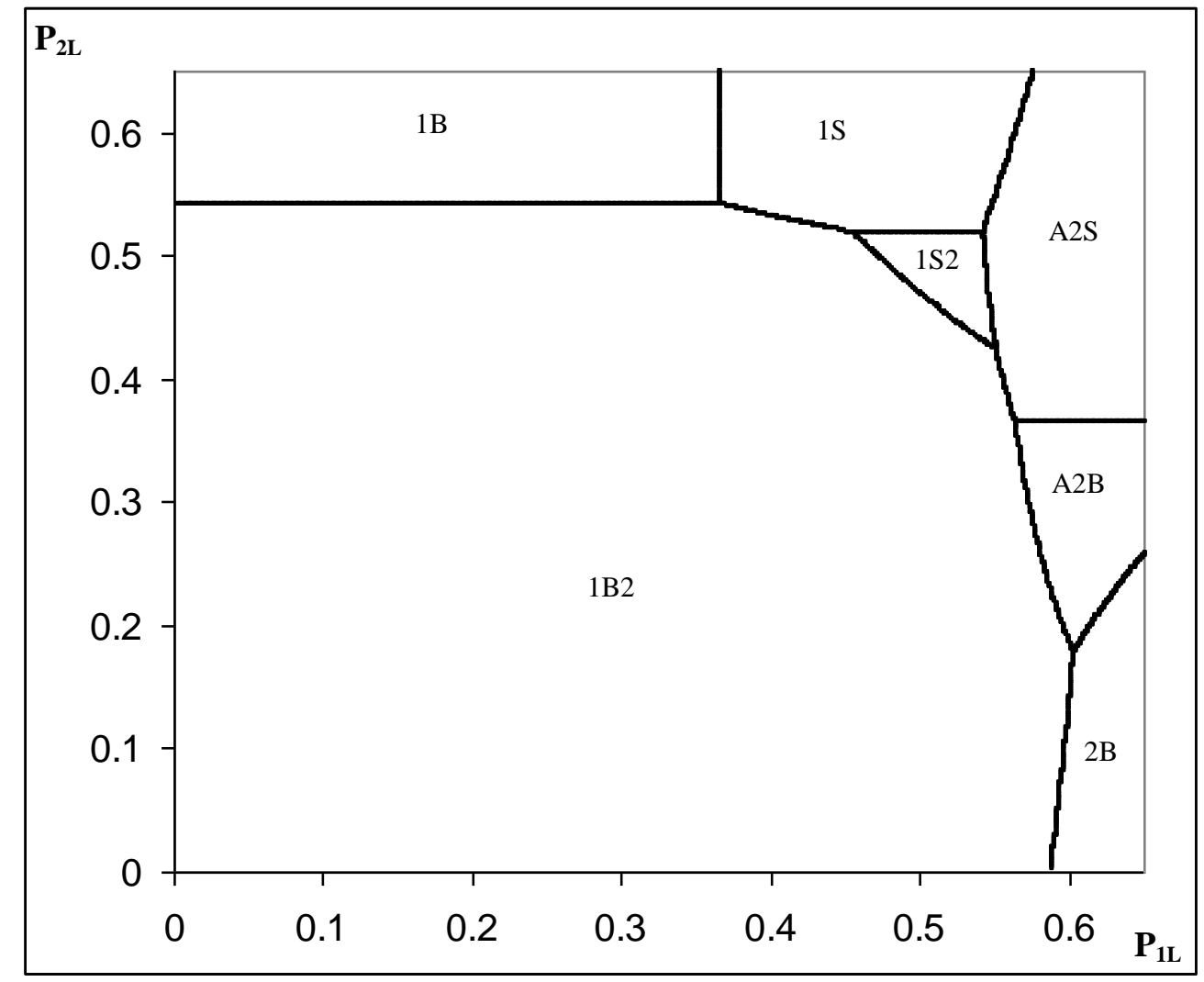

$F_{S}=4 ; F_{B}=10 ; s_{S}=2 ; s_{B}=5 ; D=0 ; D_{1}=15 ; D_{2}=5 ; E=8 ; \pi_{1}=2 / r ; \pi_{2}=1 / r ; \pi_{21}=1 ; x<-1 / r$ 
Figure 2: $r=0.045 ; \mathbf{A a}=\mathbf{1 5} \mathbf{p}$

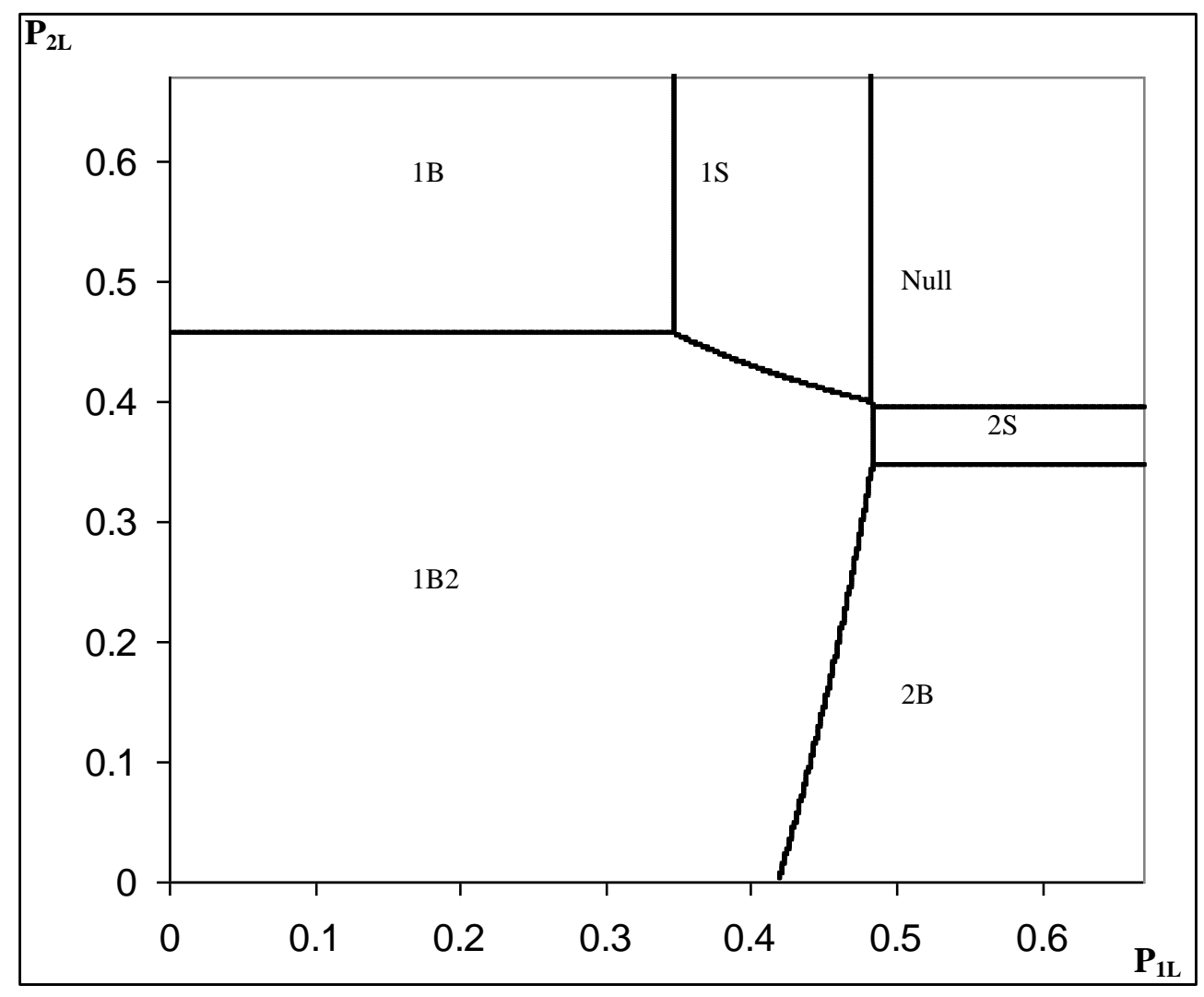


Figure 3: $r=0.03 ; \mathbf{A x}=126$

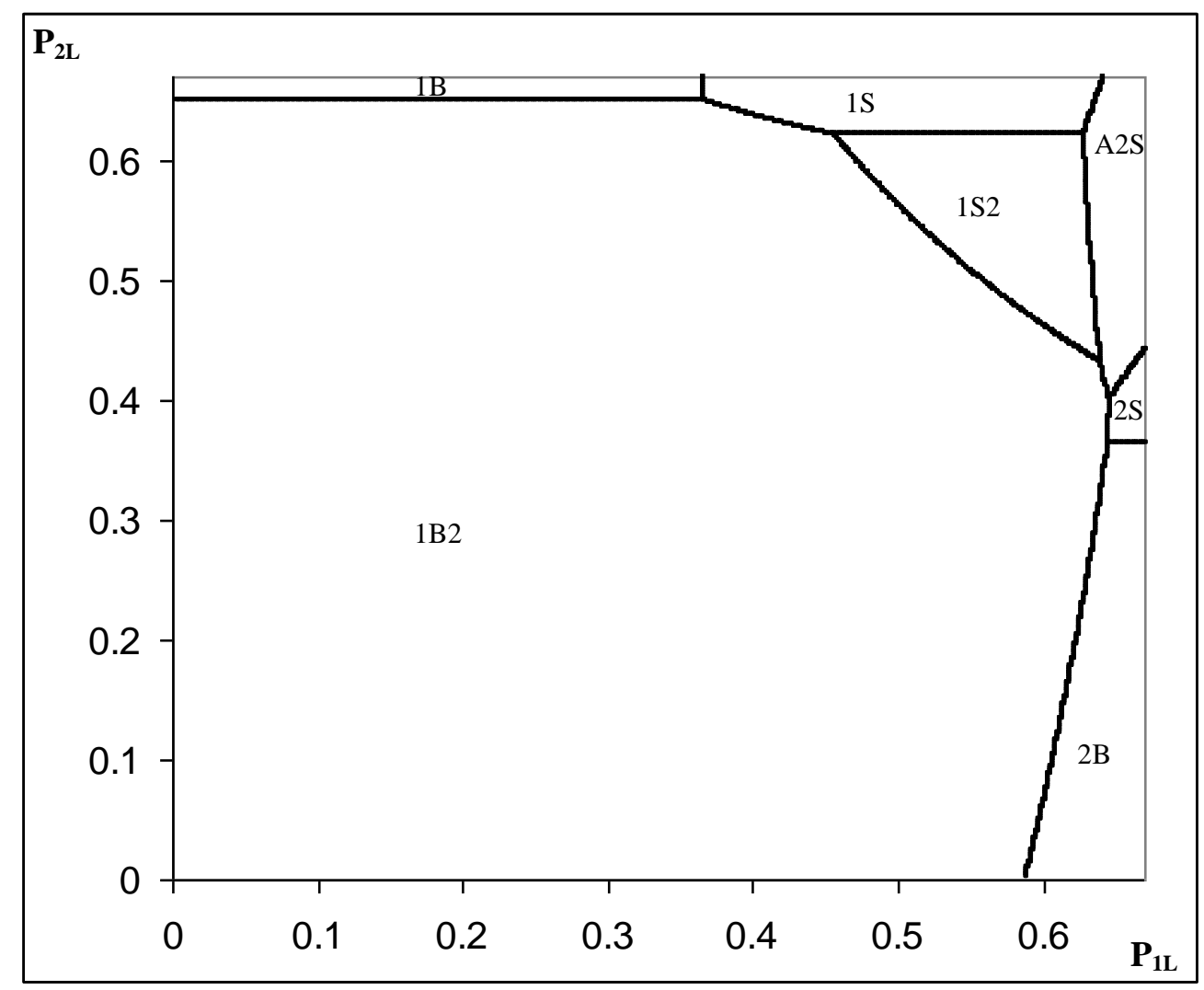




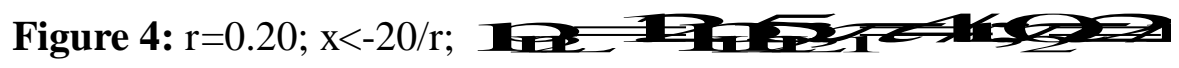

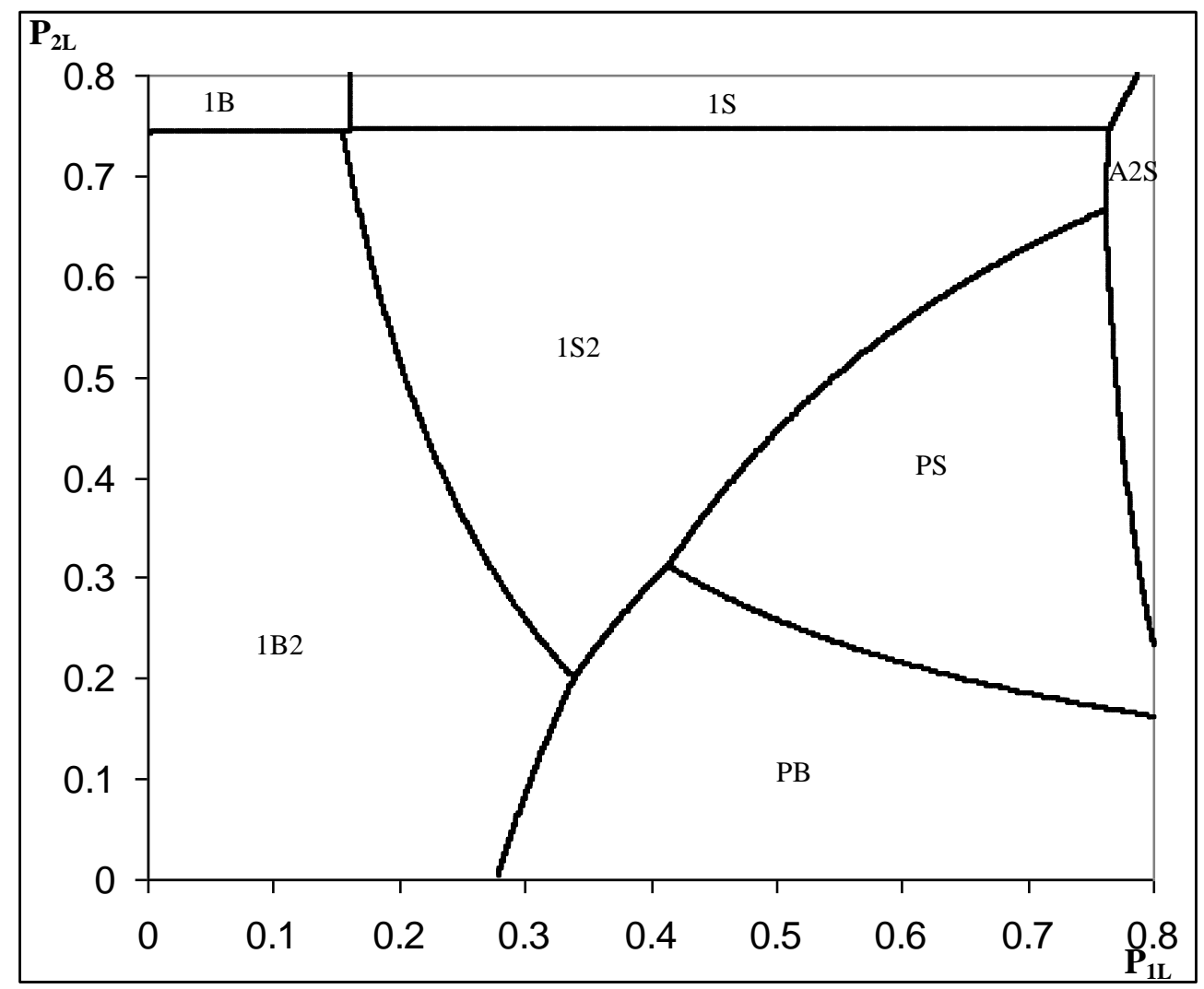

